Volume 2, Issue 2, April-June 2017, Pages: 196, DOI: http://dx.doi.org/10.19082/ah196

\title{
PREFERRED PARAMETERS OF THE OCCUPATIONAL HEALTH SURVEILLANCE SYSTEM (OSS) IN EXPERT OPINIONS OF OCCUPATIONAL STAFF: A QUALITATIVE STUDY
}

\author{
Amir Bahrami-Ahmadi' ${ }^{1}$, Mashallah Aghilinejad ${ }^{2, *}$, Elaheh Kabir-Mokamelkhah ${ }^{3}$, Jalil Kuhpaizadeh ${ }^{4}$, Leila
} Ghalichi $^{5}$

1: $\mathrm{PhD}$ by research candidate, Occupational Medicine Research Center (OMRC), Iran University of medical sciences and health services (IUMS), Tehran-Iran, bahrami.a@iums.ac.ir.

2: Associate professor, Occupational Medicine Research Center (OMRC), Iran University of medical sciences and health services (IUMS), Tehran-Iran, aghilinejad.m@iums.ac.ir.

3: Assistant professor, Occupational Medicine Research Center (OMRC), Iran University of medical sciences and health services (IUMS), Tehran-Iran, kabir.e@iums.ac.ir.

4: Professor, Occupational Medicine Research Center (OMRC), Iran University of medical sciences and health services (IUMS), Tehran-Iran, jkuhpayeh@yahoo.com

5: Associate Professor, Mental health Research Center (OMRC), Iran University of medical sciences and health services (IUMS), Tehran-Iran, ghalichi.1@iums.ac.ir

\section{Correspondence:}

Mashallah Aghilinejad; Occupational Medicine Research Center (OMRC), Iran University of medical sciences and health services (IUMS), Tehran-Iran, aghilinejad.m@iums.ac.ir

\section{TYPE OF ARTICLE: CONFERENCE ABSTRACT}

\begin{abstract}
Introduction: An Occupational Health Surveillance System (OHSS) provides a critical opportunity to monitor and evaluate occupational disorders and injuries over time. In the Islamic Republic of Iran, more than 21 million employees, work in the industrial and private sections, $62.08 \%$ and $38.03 \%$ respectively.. The present qualitative study was designed for the collection of expert opinions of staff in this filed, and to determine proper characters for a suitable Iranian OHSS.

Methods: The present qualitative study was performed on interview-based data from occupational medicine staff. Some of the questions were in reference to OHSS definition, temporary accompaniment of occupational diseases and injuries surveillance system, OHSS promoters and consumers, type of requested data for OHSS, and rewarding and controlling systems to preparing qualitative and valid OHSS data. Interview answers were read, summarized and presented.

Results: Most of the study participants' staff believed that OHSS in the scientific base must cover all essential parts including disorders, hazards and accidents collectively. They believed that this combination was made by teams working with occupational medicine staff and other specialties such as occupational hygienists and information technologists. They emphasized that the Iranian Ministry of Health had the capacity to promote OHSS and organize an executive committee with the entire OHSS involved as a team working in this filed. Occupational staff had been focused on this fact that OHSS data must cover all the required data of the Iranian working population and their relatives.

Conclusion: The Iranian occupational registry system must be changed and developed as an Occupational Health Surveillance System according to the main parameters which were found in occupational staff interviews.

KEYWORDS: Interview, Occupational medicine, Occupational staff, Parameters, Surveillance system
\end{abstract}

\section{Abstracts of First National Congress of Medical Informatics, Mashhad, Iran, February 2017}

(C) 2017 The Authors. This is an open access article under the terms of the Creative Commons Attribution-NonCommercialNoDerivs License, which permits use and distribution in any medium, provided the original work is properly cited, the use is non-commercial and no modifications or adaptations are made. 